\title{
The role of preoperative computed tomography in surgical planning of intertrochanteric femur fractures fixation
}

\author{
El Sayed A. Abdullah*, Mina E. Salama
}

Department of Orthopedic Surgery, Faculty of Medicine, Alexandria University, Alexandria, Egypt

Received: 27 January 2021

Revised: 18 February 2021

Accepted: 22 February 2021

\author{
*Correspondence: \\ Dr. El Sayed A. Abdullah, \\ E-mail: sayed_halim@yahoo.com
}

Copyright: (C) the author(s), publisher and licensee Medip Academy. This is an open-access article distributed under the terms of the Creative Commons Attribution Non-Commercial License, which permits unrestricted non-commercial use, distribution, and reproduction in any medium, provided the original work is properly cited.

\begin{abstract}
Background: A precise preoperative evaluation of stability of intertrochanteric fractures is crucial for surgical planning. Three dimensional CT scanning is a useful tool for understanding the exact type of fracture pattern.

Methods: A prospective study included 40 patients with intertrochanteric femoral fractures. They were classified into stable and unstable intertrochanteric fractures according to the X-ray based AO/OTA classification and according to Nakano 3D-CT classification and both classifications were correlated. The patients were operated on using dynamic hip screw (DHS) and were assessed radiologically and clinically by Harris hip score (HHS) after 6 months.

Results: There was significant statistical difference $(\mathrm{p}=0.031)$ and relation $(\mathrm{p}<0.001)$ between X-ray based AO/OTA classification and 3D-CT classification. Six cases from the 24 cases with stable pattern in AO/OTA system have unstable patterns in the 3D-CT $(25 \%)$ and their percent from the 22 unstable patterns in 3D-CT is $27.27 \%$ and their percent from the total number of patients in the study is $15 \%$.

Conclusions: The superolateral support in the form of the greater trochanter which affects the lateral wall thickness is as important as the posteromedial lesser fragment in assessing the stability of the fracture pattern.
\end{abstract}

Keywords: Intertrochanteric fracture, Dynamic hip screw, Harris hip score

\section{INTRODUCTION}

Intertrochanteric fractures are common problem especially in the elderly and are becoming more frequent as the proportion of the elderly in the population increases. Sometimes these fractures can become life-threatening disasters during or after treatment in the elderly. ${ }^{1}$

Surgery is the treatment of choice for both stable and unstable intertrochanteric fractures, with the goal of stable fixation to allow early mobilization and to restore the patient's previous level of activity.,3

Dynamic hip screws have been widely used for the treatment of these fractures because of their biomechanical advantages. ${ }^{4}$ Factors contributing to fixation failures in intertrochanteric fractures using dynamic hip screws are facture stability, comminution, osteoporosis, the type of reduction and surgical techniques. These factors have been involved in the difficulty in achieving and maintaining stable reduction and rigid internal fixation of unstable fractures. ${ }^{5}$

Thus, a precise preoperative evaluation of stability in intertrochanteric fractures is important for surgical planning. Three dimensional CT scanning is a useful tool for understanding the exact type of fracture pattern.

There are many classification systems for these fractures based on plain X-ray findings including the Evans system, the Jensen's system, the AO/OTA system, and the Boyd and Griffin system. ${ }^{6-10}$ 
Nakano proposed a 3D-CT classification system in Japan to avoid misunderstanding of the fracture pattern by plain $\mathrm{X}$-rays because femoral trochanteric fractures are sometimes very difficult to precisely diagnose. ${ }^{11}$

The objective of our study was to evaluate the role of preoperative computed tomography in surgical planning for fixation of intertrochanteric fractures.

\section{METHODS}

A prospective study included 40 patients with intertrochanteric femoral fractures admitted in El-Hadra University Hospital, Alexandria, Egypt. Informed consent was taken from each patient included in the study and they were subjected to history taking, physical examination, necessary laboratory investigation and imaging by X-ray and CT. They were classified into stable and unstable intertrochanteric fractures according to the X-ray based AO/OTA classification and according to Nakano 3D-CT classification..$^{9,11}$

The 3D-CT classification was based on the combination of four major fragments: the head $(\mathrm{H})$, greater trochanter $(\mathrm{G})$, lesser trochanter $(\mathrm{L})$, and shaft $(\mathrm{S})$. Each fracture was classified as a two-, three-, or four- part fracture. The three part fractures are sub grouped according to the fracture pattern of the greater and lesser trochanters into five subgroups. The first subgroup 3-part G (S) involved a small fragment of the greater trochanter, where $S$ indicates small. The second subgroup 3-part G (B) involved a big oblique fragment of the greater trochanter that does not include the lesser trochanter, where $\mathrm{B}$ indicates big. The third subgroup 3-part G-L involves a large oblique fragment of the greater trochanter including the lesser trochanter. The fourth subgroup 3-part G (W) involves a fragment of the whole greater trochanter, but the lesser trochanter is intact, where $\mathrm{W}$ indicates whole. Finally, the fifth subgroup 3-part L comprises fractures of the lesser trochanter. These fractures do not involve the greater trochanter (Figure 1).

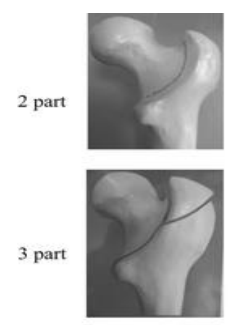

$\mathrm{G}(\mathrm{S})$

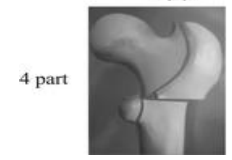

Figure 1: Fracture classification with threedimensional computed tomography (3D-CT). ${ }^{11}$

The percentage of fracture patterns classified as unstable fractures in CT and were previously classified as stable fractures in X-rays was calculated and the correlation between x-ray based AO/OTA classification and 3D-CT classification was analysed. They were operated on using DHS and were followed up radiologically (to calculate tip apex distance, analyse lag screw position in the neck and assess collapse at the fracture site and changes in the neckshaft angle) and clinically by Harris Hip Score (HHS) after 6 months. ${ }^{12-15}$ HHS was correlated with age, sex, mode of trauma, co-morbidities, job, time lapse before surgery, Xray based classification and CT based classification, lag position in the neck, neck shaft angle, collapse, medialization and union time.

Data were fed to the computer and analysed using IBM SPSS software package version 20.0. (Armonk, NY: IBM Corp). The Kolmogorov- Smirnov was used to verify the normality of distribution of variables. Comparisons between groups for categorical variables were assessed using Chi-square test (Monte Carlo). Student t-test was used to compare two groups for normally distributed quantitative variables while ANOVA test was used for comparing more than two studied groups. Comparisons between the different stages for categorical variables were assessed using McNemar test. Pearson coefficient correlate between two normally distributed quantitative variables. Significance of the obtained results was judged at the $5 \%$ level.

\section{RESULTS}

Out of 40 patients, 17 were males and 23 were females. The mean age was $61.95 \pm 14.68$ ranging from 27.0 to 90.0 . The mean time for union was $10.53 \pm 2.31$ ranging from 6 to 14 weeks (Table 1 ).

Table 1: Distribution of the studied cases according to different parameters.

\begin{tabular}{|ll|}
\hline Sex & $\mathbf{N}(\%)$ \\
\hline Male & $(\mathrm{n}=40)$ \\
\hline Female & $17(42.5 \%)$ \\
\hline Age (years) & $23(57.5 \%)$ \\
\hline Median (Min.-Max.) & $(\mathrm{n}=40)$ \\
\hline Mean \pm SD. & $65.5(27-90)$ \\
\hline Union Time (weeks) & $62 \pm 14.7$ \\
\hline Median (Min.-Max.) & $(\mathrm{n}=38 \#)$ \\
\hline Mean \pm SD. & $10(6-14)$ \\
\hline
\end{tabular}

\#: Two cases died before the end of follow up.

The 40 patients were classified according to the fracture pattern in X-rays using AO/OTA system into 24 patients with stable A1 pattern $(60 \%)$ and 16 patients with unstable A2 pattern $(40 \%)$. The 40 patients were classified according to the fracture pattern in 3D-CT using Nakano Classification system into 18 patients with stable patterns $(45 \%)$ and 22 patients with unstable patterns $(55 \%)$. There was significant statistical difference $(\mathrm{p}=0.031)$ and relation 
$(\mathrm{p}<0.001)$ between $\mathrm{X}$-ray based AO/OTA classification and 3D-CT classification (Table 2, 3).

Table 2: Comparison between X-ray and CT in classification of fracture patterns $(n=40)$.

\begin{tabular}{|c|c|c|c|}
\hline & $X-r a y(n=40)$ & CT $(n=40)$ & \multirow{2}{*}{$\mathrm{McN}_{\mathbf{p}}$} \\
\hline & $\mathbf{N}(\%)$ & $\mathbf{N}(\%)$ & \\
\hline Unstable & $16(40)$ & $22(55)$ & \multirow{2}{*}{$0.031 *$} \\
\hline Stable & $24(60)$ & $18(45)$ & \\
\hline
\end{tabular}

McN: McNemar test, *: Statistically significant at $\mathrm{p} \leq 0.05$

The 22 patients with unstable fracture patterns in 3D-CT were sub classified into 3 patients with 3 -part $\mathrm{G}(\mathrm{W})$ fracture $(13.64 \%), 11$ patients with 3-part G-L fracture (50\%), 7 patients with 3 -part $\mathrm{L}$ fracture $(31.82 \%)$ and 1 patient with 4-part fracture $(4.54 \%)$.

We found that 6 cases from the 24 cases with stable pattern in AO/OTA system have unstable patterns in the 3D-CT $(25 \%)$ and their percent from the 22 unstable patterns in 3D-CT is $27.27 \%$ and their percent from the total number of patients in the study is $15 \%$. These 6 patients $(100 \%)$ had the fracture pattern 3-part G-L in the 3D-CT classification system. This fracture type is recognized as unstable in the 3D-CT classification but was often classified as stable in AO/OTA X-ray classification (Figure 2).

Table 3: Relation between X-ray and CT classifications $(n=40)$.

\begin{tabular}{|c|c|c|c|c|}
\hline \multirow{3}{*}{ CT } & X-ray & & \multirow{3}{*}{$\mathrm{X}^{2}$} & \multirow{3}{*}{$P$ value } \\
\hline & Unstable $(n=16)$ & Stable $(n=24)$ & & \\
\hline & No. $(\%)$ & No. (\%) & & \\
\hline Unstable & $16(100 \%)$ & $6(25 \%)$ & \multirow{2}{*}{$21.818^{*}$} & \multirow{2}{*}{$<0.001 *$} \\
\hline Stable & $0(0 \%)$ & $18(75 \%)$ & & \\
\hline
\end{tabular}

$\chi 2$ : Chi square test, $\mathrm{p}$ : $\mathrm{p}$ value for comparing between the two studied categories, *Statistically significant at $\mathrm{p} \leq 0.05$
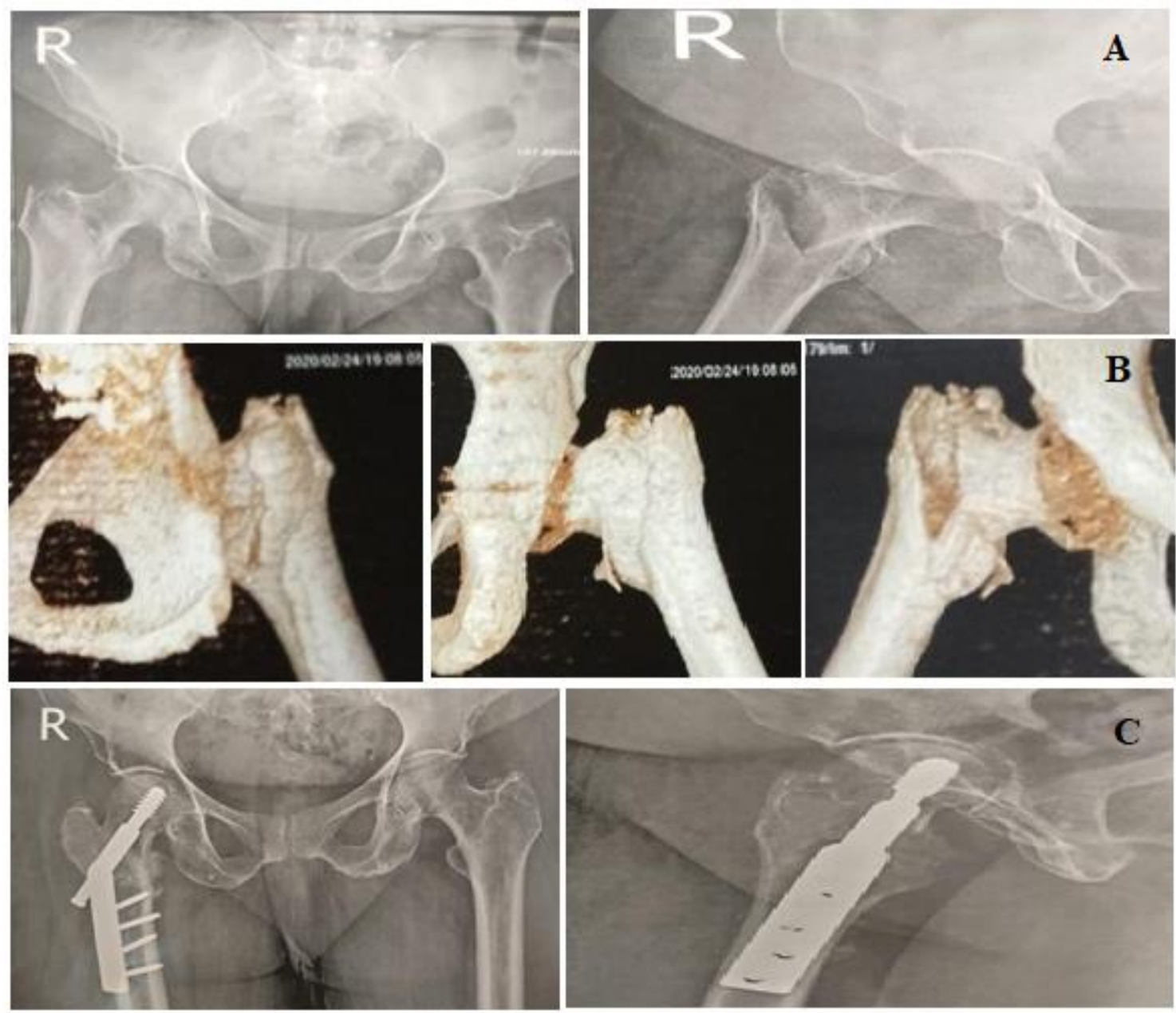

Figure 2: (A) Preoperative radiographs of a 68-year-old female patient presented with right A1 stable intertrochanteric fracture (B) preoperative 3D-CT showed 3-part G-L unstable pattern (C) radiographs after 6 months follow up and HHS was 87 (good) 


\section{Clinical assessment at the end of follow up}

Two cases died before completing the 6 months' postoperative follow up period without known complication from surgery and were excluded from clinical evaluation at the end of follow up.

Harris Hip Score calculated after 6 months from surgery was satisfactory in 35 cases ( 8 were excellent and 27 were good) $(92.1 \%)$ and unsatisfactory in 3 cases $(7.9 \%)$. The mean HHS was $86.34 \pm 5.35$.

There was an inverse significant correlation between HHS and the age of patients $(\mathrm{p}=0.002)$ and between HHS and union time $(p=0.023)$ but there was an inverse insignificant correlation between HHS and time lapse before surgery $(\mathrm{p}=0.477)($ Table 4$)$.

Table 4: Correlation between HHS and different parameters $(n=38 \#)$.

\begin{tabular}{|lll|}
\hline & HHS \\
\hline Age (years) & r & P value \\
\hline $\begin{array}{l}\text { Time lapse before } \\
\text { surgery (days) }\end{array}$ & $-0.486^{*}$ & $0.002^{*}$ \\
\hline Union time (weeks) & -0.119 & 0.477 \\
\hline
\end{tabular}

r: Pearson coefficient, *: Statistically significant at $\mathrm{p} \leq 0.05$, \#: two cases died before the end of follow up

There was no significant statistical difference between both sexes in relation to HHS $(\mathrm{p}=0.065)$. There was significant statistical relation between HHS and mode of trauma, patients' comorbidities, job, X-ray based AO/OTA classification and 3D-CT classification $(\mathrm{p}=0.012,0.016,0.001,0.004$ and 0.001 respectively) (Table 5).

\section{Radiological assessment at the end of follow up}

Two cases died before completing the 6 months' postoperative follow up period without known complication from surgery and were excluded from the radiological evaluation at the end of follow up.

Tip apex distance was less than $25 \mathrm{~mm}$ in all cases. Lag screw position in the neck was central in 20 cases $(52.63 \%)$ and inferior in 18 cases (47.37\%). There was no significant statistical difference between the two positions in relation to the mean HHS $(\mathrm{p}=0.505)$ and there was no significant statistical relation between HHS and neck shaft angle or between HHS and degree of fracture collapse $(\mathrm{p}=0.100$, 0.124 respectively) (Table 5).

Neck shaft angle was normal in 27 cases $(71.05 \%)$, in varus in 8 cases $(21.05 \%)$ and in valgus in 3 cases $(7.9 \%)$ in comparison to the normal contralateral side. There was no significant statistical relation between $\mathrm{X}$-ray based AO/OTA classification and neck shaft angle ( $\mathrm{p} 1=0.119)$. There was no significant statistical relation between 3DCT classification and neck shaft angle ( $1=0.123)$.

There was no significant statistical difference between Xray based AO/OTA and 3D-CT classification according to neck shaft angle $(\mathrm{p}=0.500,0.250)$ (Table 6$)$.

Table 5: Relation between HHS and different parameters ( $n=38 \#)$.

\begin{tabular}{|c|c|c|c|c|c|}
\hline & & HHS & & & \\
\hline & $\mathbf{N}$ & Mean \pm SD & Median (Min.-Max.) & Test of sig. & P value \\
\hline Sex & & & & & \\
\hline Male & 17 & $88.1 \pm 5.6$ & $89(80-100)$ & & \\
\hline Female & 21 & $84.9 \pm 4.8$ & $85(75-93)$ & $\mathrm{t}=1.905$ & 0.065 \\
\hline Mode of trauma & & & & & \\
\hline Low energy trauma & 33 & $85.5 \pm 4.7$ & $87(75-94)$ & $t-2638 *$ & ก012* \\
\hline High energy trauma & 5 & $91.8 \pm 6.9$ & $93(81-100)$ & $t=2.050^{\circ}$ & 0.012 \\
\hline Co-morbidities & & & & & \\
\hline No & 18 & $88.5 \pm 6.1$ & $89(75-100)$ & t-2 525* & $0016 *$ \\
\hline Yes & 20 & $84.4 \pm 3.8$ & $84.5(75-91)$ & $=2.525^{\prime \prime}$ & $0.010^{\circ}$ \\
\hline Job & & & & & \\
\hline Non-worker & 30 & $85 \pm 4.5$ & $85(75-93)$ & $-2507 *$ & $0001 *$ \\
\hline Worker & 8 & $91.5 \pm 5.5$ & $92.5(81-100)$ & l=5.50/ & $0.001^{2}$ \\
\hline X-ray & & & & & \\
\hline Unstable & 16 & $83.5 \pm 4$ & $83.5(75-93)$ & $t=3100 *$ & $0004 *$ \\
\hline Stable & 22 & $88.4 \pm 5.3$ & $89(75-100)$ & $l=3.102^{*}$ & $0.004^{*}$ \\
\hline CT & & & & & \\
\hline Unstable & 21 & $83.8 \pm 4.4$ & $84(75-93)$ & $t-3783 *$ & $0001 *$ \\
\hline Stable & 17 & $89.5 \pm 4.8$ & $89(79-100)$ & $=5.105$ & 0.001 \\
\hline Lag position & & & & & \\
\hline Central & 20 & $86.9 \pm 5.5$ & $87.5(75-94)$ & $t=0.673$ & 0.505 \\
\hline
\end{tabular}

Continued. 


\begin{tabular}{|c|c|c|c|c|c|}
\hline & \multirow{2}{*}{$\mathbf{N}$} & \multicolumn{2}{|l|}{ HHS } & \multirow{2}{*}{ Test of sig. } & \multirow{2}{*}{ P value } \\
\hline & & Mean \pm SD & Median (Min.-Max.) & & \\
\hline Inferior & 18 & $85.7 \pm 5.3$ & $85(75-100)$ & & \\
\hline \multicolumn{6}{|c|}{ Neck shaft angle } \\
\hline Normal & 27 & $87 \pm 5.9$ & $87(75-100)$ & \multirow{3}{*}{$\mathrm{F}=1.810$} & \multirow{3}{*}{0.100} \\
\hline In Varus & 8 & $85.4 \pm 3.8$ & $85.5(80-91)$ & & \\
\hline In Valgus & 3 & $82.7 \pm 1.5$ & $83(81-84)$ & & \\
\hline \multicolumn{6}{|l|}{ Collapse } \\
\hline$<1 \mathrm{~cm}$ & 28 & $87.5 \pm 5.3$ & $87(75-100)$ & \multirow{3}{*}{$\mathrm{F}=1.706$} & \multirow{3}{*}{0.124} \\
\hline $1-2 \mathrm{~cm}$ & 8 & $84.8 \pm 3.2$ & $84.5(80-89)$ & & \\
\hline$>2 \mathrm{~cm}$ & 2 & $77 \pm 2.8$ & $77(75-79)$ & & \\
\hline \multicolumn{6}{|c|}{ Medialization } \\
\hline No & 24 & $88 \pm 5.5$ & $88(75-100)$ & \multirow{2}{*}{$\mathrm{t}=2.707^{*}$} & \multirow{2}{*}{$0.010^{*}$} \\
\hline Yes & 14 & $83.5 \pm 3.9$ & $84(75-89)$ & & \\
\hline
\end{tabular}

$\mathrm{t}$ : Student t-test F: F for ANOVA test, p: p value for comparing between the different studied categories, *: Statistically significant at $\mathrm{p} \leq 0.05$, \#: Two cases died before the end of follow up
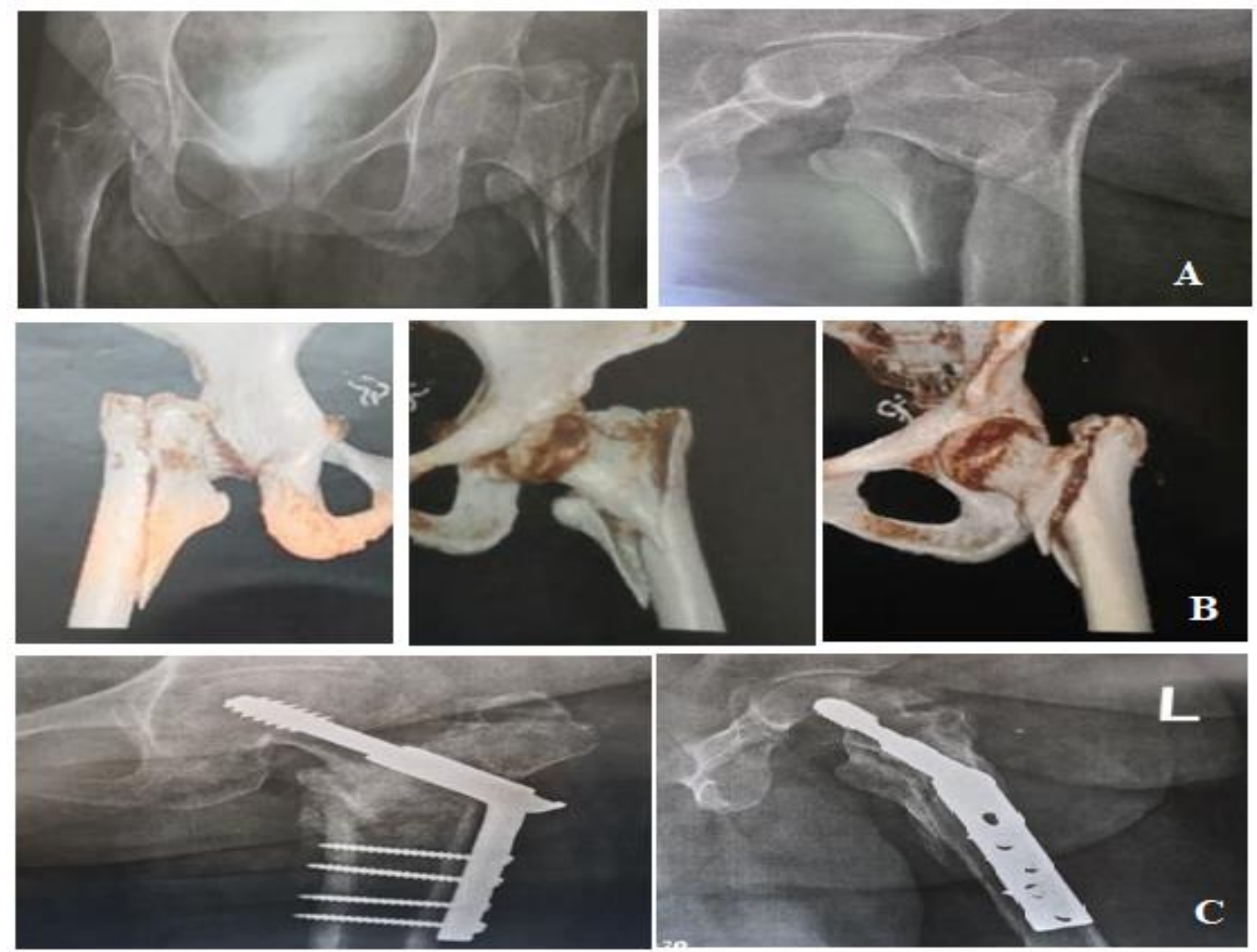

Figure 3: (A) Preoperative radiographs of a 70-year-old female patient with left A2 unstable intertrochanteric fracture (B) preoperative 3D-CT showed 3-part G-L unstable pattern (C) radiographs after 6 months follow up and HHS was 82 (good).

Table 6: Comparison between X-ray and CT classification according to neck shaft angle, degree of collapse and medialization (\% from row).

\begin{tabular}{|c|c|c|c|c|c|c|}
\hline & \multirow{2}{*}{$\mathbf{N}$} & \multicolumn{2}{|l|}{ X-ray (n=38\#) } & \multicolumn{2}{|l|}{ CT (n=38\#) } & \multirow{2}{*}{$\mathrm{McNp}$} \\
\hline & & Unstable N (\%) & Stable N (\%) & Unstable N (\%) & Stable N (\%) & \\
\hline \multicolumn{7}{|c|}{ Neck shaft angle } \\
\hline Normal & 27 & $10(37)$ & $17(63)$ & $12(44.4)$ & $15(55.6)$ & 0.500 \\
\hline In Varus & 8 & $3(37.5)$ & $5(62.5)$ & $6(75)$ & $2(25)$ & 0.250 \\
\hline In Valgus & 3 & $3(100)$ & $0(0)$ & $3(100)$ & $0(0)$ & - \\
\hline $\mathrm{X}^{2}(\mathrm{MCp} 1)$ & & $4.015(0.119)$ & & $4.442(0.123)$ & & \\
\hline
\end{tabular}




\begin{tabular}{|c|c|c|c|c|c|c|}
\hline & \multirow{2}{*}{$\mathbf{N}$} & \multicolumn{2}{|l|}{ X-ray (n=38\#) } & \multicolumn{2}{|l|}{ CT (n=38\#) } & \multirow{2}{*}{ McNp } \\
\hline & & Unstable N (\%) & Stable N (\%) & Unstable N (\%) & Stable N (\%) & \\
\hline \multicolumn{7}{|c|}{ Degree of collapse } \\
\hline$<1 \mathrm{~cm}$ & 28 & $9(32.1)$ & $19(67.9)$ & $14(50)$ & $14(50)$ & 0.063 \\
\hline $1-2 \mathrm{~cm}$ & 8 & $6(75)$ & $2(25)$ & $6(75)$ & $2(25)$ & 1.000 \\
\hline$>2 \mathrm{~cm}$ & 2 & $1(50)$ & $1(50)$ & $1(50)$ & $1(50)$ & 1.000 \\
\hline $\mathrm{X}^{2}(\mathrm{MCp} 1)$ & & $4.784(0.092)$ & & $1.753(0.530)$ & & \\
\hline \multicolumn{7}{|c|}{ Medialization } \\
\hline No & 24 & $6(25)$ & $18(75)$ & $10(41.7)$ & $14(58.3)$ & 0.125 \\
\hline Yes & 14 & $10(71.4)$ & $4(28.6)$ & $11(78.6)$ & $3(21.4)$ & 1.000 \\
\hline $\mathrm{X}^{2}(\mathrm{p} 1)$ & & $7.819 *\left(0.005^{*}\right)$ & & $4.871^{*}(0.027 *)$ & & \\
\hline
\end{tabular}

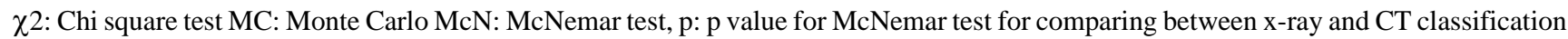
according to neck shaft angle, degree of collapse and medialization, $\mathrm{p} 1$ : $\mathrm{p}$ value for Chi square test for comparing between different categories of neck shaft angle, degree of collapse and medialization in relation to x-ray and CT classification, *: Statistically significant at $\mathrm{p} \leq 0.05$, \#: Two cases died before the end of follow up

Table 7 Relation between medialization and degree of collapse $(\mathrm{cm})(\mathrm{n}=38 \#)$.

\begin{tabular}{|c|c|c|c|c|c|}
\hline \multirow{2}{*}{ Degree of collapse } & \multirow{2}{*}{$\mathbf{N}$} & \multicolumn{2}{|l|}{ Medialization } & \multirow{2}{*}{$\mathrm{X}^{2}$} & \multirow{2}{*}{$\mathrm{MCp}$} \\
\hline & & No $(n=24)$ N $(\%)$ & Yes $(n=14)$ N $(\%)$ & & \\
\hline$<1 \mathrm{~cm}$ & 28 & $24(85.7)$ & $4(14.3)$ & \multirow{3}{*}{$22.904^{*}$} & \multirow{3}{*}{$<0.001 *$} \\
\hline $1-2 \mathrm{~cm}$ & 8 & $0(0)$ & $8(100)$ & & \\
\hline$>2 \mathrm{~cm}$ & 2 & $0(0)$ & $2(100)$ & & \\
\hline
\end{tabular}

$\chi 2$ : Chi square test MC: Monte Carlo, $\mathrm{p}$ : $\mathrm{p}$ value for comparing between the two studied categories, *: Statistically significant at $\mathrm{p} \leq 0.05$, \#: Two cases died before the end of follow up

On comparing the immediate postoperative and 6 months' follow up radiographs: minimal collapse $<1 \mathrm{~cm}$ occurred in 28 cases $(73.68 \%)$, moderate collapse $1-2 \mathrm{~cm}$ occurred in 8 cases $(21.06 \%)$ and severe collapse $>2 \mathrm{~cm}$ occurred in 2 cases $(5.26 \%)$. There was no significant statistical relation between X-ray based AO/OTA classification and degree of collapse $(\mathrm{p} 1=0.092)$. There was no significant statistical relation between 3D-CT classification and degree of collapse $(\mathrm{p} 1=0.530)$. There was no significant statistical difference between X-ray based AO/OTA and 3D-CT classification according to degree of collapse $(\mathrm{p}=0.063,1.000,1.000)$ (Table 6).

Medialization occurred in 14 cases in our study (36.8\%). Intraoperative lateral wall fracture occurred in 8 cases (38\%) from the 21 patients with intact preoperative lateral wall.

Medialization occurred in 9 cases $(53 \%)$ at the end of follow up from 17 patients with preoperative lateral wall fracture. These 9 cases are distributed as 2 cases 3-part $\mathrm{G}(\mathrm{S})$ fracture, 2 cases 3-part G(W) fracture, 4 cases 3-part G-L fracture and 1 case 4-part fracture. It is noted that 3part G-L pattern is involved in $45 \%$ of these cases (Figure 3).

Medialization occurred in 5 cases (62.5\%) from the 8 cases in which intraoperative lateral wall fracture occurred and it's percent from the 21 cases with intact preoperative lateral wall is $24 \%$. The fracture pattern of these 5 cases is as follow: 4 cases with 3-part L fracture pattern $(80 \%)$ and 1 case with 2-part fracture (20\%).
There was significant statistical difference between the mean HHS of patients in which medialization occurred and the mean HHS of patients in which medialization didn't occur $(\mathrm{p}=0.010)$ (Table 5).

There was significant statistical relation between X-ray based AO/OTA classification and occurrence of medialization $(\mathrm{p} 1=0.005)$. There was significant statistical relation between 3D-CT classification and occurrence of medialization $(\mathrm{p} 1=0.027)$. There was no significant statistical difference between X-ray based AO/OTA and 3D-CT classification according to occurrence of medialization or not $(\mathrm{p}=0.125,1.000)$ (Table 6).

There was significant statistical relation between degree of collapse and medialization $(\mathrm{p}<0.001)$ (Table 7).

\section{DISCUSSION}

Unstable trochanteric fractures may be because of large posteromedial separate fragment, a reverse obliquity pattern, subtrochanteric extension or a displaced greater trochanter (lateral wall fracture). Of these patterns, 3-part $\mathrm{G}-\mathrm{L}$ type fracture is considered to have large posteromedial separate fragment. So 3-part G-L type is recognized as unstable type because of this definition. However, classification of this fracture using plain X-ray is impossible.

In this study, we found that 6 cases from the 24 cases with stable pattern in AO/OTA system have unstable patterns in the 3D-CT $(25 \%)$ and their percent from the 22 unstable patterns in $3 \mathrm{D}-\mathrm{CT}$ is $27.27 \%$ and their percent from the 
total number of patients in the study is $15 \%$. The 6 cases $(100 \%)$ were of the 3-part G-L pattern.

These results were comparable to the results of Etsuo Shoda et al who conducted a study in 2017 on 239 patients with intertrochanteric fractures and these fractures were classified according to AO/OTA system and 3D-CT system. ${ }^{16}$ One hundred and twenty-three cases were unstable fractures in the 3D-CT system in their study $(51.5 \%)$ in comparison to 22 cases in our study (55\%).

In their study, 50 cases of 165 patients with stable fractures in the AO/OTA classification $(30.3 \%)$ were classified as unstable in the $3 \mathrm{D}-\mathrm{CT}$ system. ${ }^{16}$ Their percent from the unstable patterns in the 3D-CT system is $41 \%$ and their percent from the total number of patients in the study is $21 \%$. 44 of these 50 cases $(80 \%)$ were of the 3 -part G-L pattern.

Lag screw cut-out didn't occur in any case in our study and this is consistent with TAD less than $25 \mathrm{~mm}$ in postoperative radiographs of the cases in our study. This is comparable to the study conducted by Baumgaertner et al in 1995 when none of 120 screws with TAD less than 25 mm cut out. ${ }^{12}$

The mean HHS in our study is $86.34 \pm 5.35$ which is higher than the mean score (84.5) in the study conducted by Vinay Kumar on 20 patients with intertrochanteric fractures fixed by DHS as lag screw cut out occurred in one patient of their study and infection occurred in another one. ${ }^{17}$

In our study, satisfactory Harris Hip Score was achieved in 35 cases $(92.1 \%)$ in the form of 8 excellent and $27 \operatorname{good}$ scores. 3 cases $(7.9 \%)$ showed unsatisfactory fair scores. Rakesh Kumar et al conducted a study in 2019 on 64 patients with intertrochanteric fractures fixed by DHS. ${ }^{18}$ HHS was calculated 9 months after surgery. Satisfactory score was achieved in 50 cases $(78.1 \%)$ in the form of 37 excellent and 13 good scores.14 cases (21.9\%) showed unsatisfactory score in the form of 9 fair and 5 poor scores. Non-union occurred in two cases and lag cut out occurred in one case in their study.

Our study showed that there is no statistical significant relation between X-ray based AO/OTA classification and degree of collapse and no statistical significant relation between 3D-CT classification and degree of collapse but there is statistical significant relation between degree of collapse and medialization.

Sharma et al mismatched these results in their study in 2014. ${ }^{19}$ It showed statistical significant relation between degree of fracture collapse and X-ray based AO/OTA and 3D-CT classification as they studied in the 3D-CT the morphology of the posteromedial fragment regarding size and displacement as well as the size of greater trochanter fractured as the size of the greater trochanter cannot be estimated on the X-rays. Involvement of the greater trochanter is increasingly being recognized as a risk factor for lateral wall fracture after DHS resulting in collapse at fracture site and shaft medialization if the posteromedial lesser trochanter fragment is large and displaced. ${ }^{20}$ Their study also showed that as long as the lateral wall is intact, fracture collapse is minimal and is not affected by the size, fragmentation or the displacement of the lesser trochanter fragment. $^{19}$

In our study, there was no statistical significant difference between the mean HHS in cases with minimal, moderate or severe collapse. Fracture collapse affects the gait of the patient due to affecting the abductor lever arm but the gait shares by only 11 from the 100 points in the HHS.

In our study medialization occurred in 5 cases $(62.5 \%)$ from the 8 cases in which intraoperative lateral wall fracture occurred and there is statistical significant difference between the mean HHS in patients in which medialization occurred and the mean HHS in patients in which medialization didn't occur as the mean score in patients without medialization is higher this can be compared to the study conducted by Pradeep et al on 135 patients with intertrochanteric fractures fixed by DHS in 2014 in which medialization occurred in 22 patients $(65 \%)$ from 34 patients with intraoperative lateral wall fracture but they calculated HHS 12 months after surgery. ${ }^{21}$

\section{CONCLUSION}

We can suggest using 3D-CT classification system for intertrochanteric fractures for better assessment of the fracture pattern of the greater trochanter, particularly large oblique fragments that include the lesser trochanter $(\mathrm{G}-\mathrm{L})$ which is difficult to be visualized on plain X-rays. 3D-CT delineates the fracture line clearly to classify the fracture pattern easily.

The superolateral support in the form of the greater trochanter which affects the lateral wall thickness is as important as the posteromedial lesser fragment in assessing the stability of the fracture pattern.

Funding: No funding sources

Conflict of interest: None declared

Ethical approval: The study was approved by the institutional ethics committee

\section{REFERENCES}

1. Laskin R, Gruber M, Zimmerman A. Intertrochanteric fractures of the hip in the elderly: a retrospective analysis of 236 cases. Clin Orthop Relat Res. 1979;141:188-95.

2. Evans E. The treatment of trochanteric fractures of the femur. J Bone Joint Surg Am. 1949;31(2):190-203.

3. Koval K, Zuckerman J. Hip fractures: II. Evaluation and treatment of intertrochanteric fractures. J Am Acad Orthop Surg. 1994;2(3):150-6. 
4. Dimon J, Hughston J. Unstable intertrochanteric fractures of the hip. J Bone Joint Surg Am. 1967;49(3):440-50.

5. Kyle R, Gustilo R, Premer R. Analysis of six hundred and twenty-two intertrochanteric hip fractures. J Bone Joint Surg Am. 1979;61(2):216-21.

6. Russell T. Intertrochanteric fractures. In: Bucholz RW, Heckman JD, Court-Brown CM, et al, eds. Rockwood and green's fractures in adults. 7th ed. Philadelphia: Lippincott Williams and Wilkins; 2009:1597-640.

7. Evans E. The treatment of trochanteric fractures of the femur. J Bone Joint Surg Br. 1949;31:190-203.

8. Jensen J. Classification of trochanteric fractures. Acta Orthopaedica Scandinavica. 1980;51:803-10.

9. Marsh J, Slongo T, Agel J, Broderick J, Creevey W, DeCoster $\mathrm{T}$, et al. Fracture and dislocation classification compendium- 2007: Orthopaedic Trauma Association classification, database and outcomes committee. J Orthop Trauma. 2007;21(10):1-133.

10. Boyd H, Griffin L. Classification and treatment of trochanteric fractures. Arch Surg 1949;58:853-66.

11. Nakano T. Proximal femoral fracture. Seikeigeka (Orthopaedics). 2014;65:842-50.

12. Baumgaertner M, Curtin S, Lindskog D, Keggi J. The value of the tip-apex distance in predicting failure of fixation of peritrochanteric fractures of the hip. J. Bone Joint Surg. Am. 1995;77(7):1058-64.

13. Goffin J, Pankaj P, Simpson A. The importance of lag screw position for the stabilization of trochanteric fractures with a sliding hip screw: A subject-specific finite element study. J Orthop Res. 2013;31(4):596- 600

14. Platzer P, Thalhammer G, Wozasek G, Vécsei V. Femoral shortening after surgical treatment of trochanteric fractures in nongeriatric patients. Journal of Trauma and Acute Care Surgery. 2008;64(4):982-9.
15. Harris W. Traumatic arthritis of the hip after dislocation and acetabular fractures: treatment by mold arthroplasty. An end-result study using a new method of result evaluation. J Bone Joint Surg Am. 1969;51(4):737-55

16. Shoda E, Kitada S, Sasaki Y, Hirase H, Niikura T, Lee S, Sakurai A, Oe K, Sasaki T. Proposal of new classification of femoral trochanteric fracture by three-dimensional computed tomography and relationship to usual plain X-ray classification. J Orthopaed Surg. 2017;25(1):1-5.

17. Kumar V. Assessment of efficacy of DHS fixation in treatment of intertrochanteric fractures. J Advanc Medic Dent Sci Res. 2019;7(8):115-7.

18. Kumar R, Ranjan R, Jeyaraman M, Chaudhary D. Clinico-radiological and functional outcome of intertrochanteric fractures by dynamic hip screw. Nat J Clinic Orthopaed. 2020;4(1):19-22

19. Sharma G, Gn K, Khatri K, Singh R, Gamanagatti S, Sharma V. Morphology of the posteromedial fragment in pertrochanteric fractures: a threedimensional computed tomography analysis. Injury. 2017;48(2):419-31.

20. Palm H, Lysén C, Krasheninnikoff M, Holck K, Jacobsen S, Gebuhr P. Intramedullary nailing appears to be superior in pertrochanteric hip fractures with a detached greater trochanter: 311 consecutive patients followed for 1 year. Acta orthopaedica. 2011;82(2):166-70.

21. Pradeep A, KiranKumar A, Dheenadhayalan J, Rajasekaran S. Intraoperative lateral wall fractures during Dynamic Hip Screw fixation for intertrochanteric fractures-Incidence, causative factors and clinical outcome. Injury. 2018;49(2):334-8.

Cite this article as: Abdullah ESA, Salama ME. The role of preoperative computed tomography in surgical planning of intertrochanteric femur fractures fixation. Int J Res Orthop 2021;7:211-8. 